\title{
Exame clínico do aparelho respiratório de bezerros
}

\section{- Clinical examination of the respiratory system of calves}

* Faculdade de Medicina Veterinária e Zootecnia - UNESP - Botucatu Departamento de Clínica Veterinária Distrito de Rubiāo Júnior CEP:18618-000 - Botucatu - SP Fone: (0XX14) 6802-6293

\footnotetext{
* Roberto Calderon Gonçalves ${ }^{1}$ - CRMV-SP ${ }^{0} 1713$

Graziela Barioni ${ }^{2}$ - CRMV-SP n ${ }^{\circ} 8564$

1 Professor Assistente Doutor da Disciplina de Clínica de Grandes Animais - FMVZ - UNESP

Médica Veterinária, Doutoranda, área de Clínica Veterinária - FMVZ - UNESP
}

\section{RESUMO}

As afecções do trato respiratório estão entre as doenças mais comuns em bezerros, acarretando altas perdas econômicas decorrentes dos custos com diagnóstico, tratamento e morte dos animais. Neste trabalho são descritos os exames semiológicos para que se estabeleça o diagnóstico deste processo. São descritos como métodos semiológicos a anamnese, inspeção, palpação, percussão, auscultação e olfação; comenta-se sobre o uso de alguns métodos auxiliares de diagnóstico.

Palavras chave: Bovinos, bezerros, sistema respiratório, semiologia.

\section{Introdução}

$\underline{A}$ S afecções respiratórias são consideradas sério problema de sanidade animal, acarretando altos índices de morbidade e mortalidade, além de perdas econômicas decorrentes da baixa conversão alimentar, retardo no ganho de peso, e custos com diagnóstico e tratamento (GRIFFIN, 1997)

Um animal doente pode indicar uma doença no rebanho que, se corretamente identificada e tratada, poderá ser abreviada e prevenida (WILSON, 1992; RADOSTITS et al., 1994). Assim, é de grande importância o diagnóstico precoce de uma afecção, o tratamento adequado e a prevenção de novos episódios, não só no animal examinado, mas no rebanho como um todo.

O diagnóstico e tratamento das doenças respiratórias em animais de produção é uma constante e uma das principais atuações na clínica veterinária (PRINGLE, 1992a). Algumas delas requerem poucos recursos diagnósticos, enquanto outras exigem exames complementa- res (REBHUN et al., 1995) e até o auxílio da necropsia para o diagnóstico diferencial (PRINGLE et al., 1991).

O exame clínico, quando realizado de maneira correta, torna-se insubstituível por qualquer exame complementar e chega a ser encarado como arte por alguns autores (WILSON, 1992; REBHUN et al., 1995). Entretanto, depende de técnicas apropriadas, de cuidado, paciência e rotina lógica, que cubram todas as possibilidades eventuais (PINSENT, 1992). Por meio da anamnese, inspeção, palpação, percussão, auscultação e olfação, o clínico deve ter como finalidade a localização do processo, o estabelecimento de sua natureza, prognóstico e, se possível, sua etiologia.

\section{MÉTODOS SEMIOLÓGICOS}

\section{Anamnese ou história}

Tem o intuito de obter informações que dêem suporte ao clínico para o diagnóstico das afecções. Há ne- 
cessidade de se colher informações, de uma forma regrada, para que não se perca de vista o objetivo e se obtenham todos os dados necessários. É indiscutível a importância de uma anamnese precisa (BEECH, 1991; PINSENT, 1992; RADOSTITS et al., 1994; DIXON, 1997) e, os erros grosseiros a que pode induzir se for mal feita ou incompleta (MAREK e MÓCSY, 1965).

No exame do aparelho respiratório, é importante que se extraia da história se o problema é individual ou coletivo. Problemas num único indivíduo podem estar relacionados somente a ele, como também podem ser o início de um problema de rebanho. Desta maneira, há necessidade da observação do surgimento de casos novos e, se o problema for coletivo, deve-se investigar a morbidade e a mortalidade ou letalidade no rebanho (RADOSTITS et al., 1994).

Outros pontos importantes são as informações sobre o início do processo, o tipo e o tempo de evolução, com o objetivo de se verificar a gravidade do caso. Tratamentos anteriores ao atendimento devem ser explorados, tanto para se saber da evolução do caso clínico, como para eventuais modificações no plano terapêutico (WILSON, 1992; RADOSTITS et al., 1994).

$\mathrm{Na}$ anamnese dos problemas respiratórios, devese estabelecer uma relação estreita entre os sinais clínicos apresentados e o momento em que eles ocorrem com maior intensidade durante o manejo do animal. Assim, a tosse pode estar exacerbada ou apresentarse somente no ato da alimentação. Nesses casos, devemos colher informações dirigidas sobre o tipo de arraçoamento (pulverulento ou não) sobre a altura do cocho de alimentação, que pode provocar traumatismos constantes na traquéia ou laringe (WILSON e LOFSTEDT, 1990; BEECH, 1991). Ao contrário, o corrimento nasal pode-se mostrar mais intenso quando o animal abaixa a cabeça para comer. Isto pode não indicar um efeito da alimentação sobre a secreção nasal e, sim, um efeito físico de facilitação de drenagem. Entretanto, este pode ser um dos primeiros sinais manifestados numa alteração do aparelho respiratório (PRINGLE, 1992a).

Da mesma maneira, é importante a observação tanto da lotação, e tipo de bezerreiro, com relação à umidade, temperatura interna, ventilação e insolação, quanto do tipo de cama utilizada nestas instalações, se são pulverulentas ou se possuem agentes irritantes. Todos estes são fatores predisponentes às infecções respiratórias em bovinos, especialmente nos bezerros (JONES e WEBSTER, 1981; ANDREWS, 1992; RADOSTITS et al., 1994; RIBBLE et al., 1995). Se os animais são de campo, devese observar se os pastos são úmidos, pois podem facilitar a disseminação de Dictyocaulus viviparus (BREEZE, 1985).

Uma das primeiras finalidades do exame clínico é a localização do processo dentro do aparelho respiratório. Interessa saber se ele é alto ou baixo, ou seja, se está restrito às vias aéreas superiores (anteriores) ou às vias aéreas inferiores (posteriores) e, ainda, se inclui o parênquima pulmonar. Os métodos semiológicos favorecem o diagnóstico do local da lesão.

\section{Inspeção}

A inspeção é o método semiológico em que se faz a observação do animal como um todo e, neste caso, particularmente, do aparelho respiratório. Deve-se observar o animal de preferência sem tocá-lo, sem excitá-lo, pois isso poderá provocar modificações na freqüência respiratória e até no tipo de respiração. Para a contagem da frequiência respiratória, o observador deve-se posicionar preferencialmente na parte traseira do animal, olhando-o de um ângulo oblíquo. A frequiência respiratória normal, segundo STÖBER, (1993), para bovinos adultos é de 24 a 36 movimentos por minuto e de 30 a 45 movimentos por minuto em bezerros. WILSON e LOFSTEDT, (1990) e RADOSTITS et al., (1994) citam como sendo de 10 a 30 movimentos por minuto em bovinos, de maneira geral.

A observação da respiração, ou seja, da relação inspiração/expiração, dos movimentos do tórax e abdômen e da postura adotada pelo animal, classifica a atividade respiratória como normal (eupnéia) ou dificultosa (dispnéia). A dispnéia pode ser de grande auxílio na localização do processo respiratório. Assim, dispnéia inspiratória está relacionada a alterações nas vias aéreas superiores, seja por estenoses, corpos estranhos, inflamações ou compressões, que diminuam o lúmen das vias aéreas, dificultando a entrada de ar (PRINGLE, 1992; STÖBER, 1993). Nas doenças que determinam preenchimento do espaço pleural, dificultando a expansão pulmonar, há também manifestação de dispnéia inspiratória (RADOSTITS et al., 1994) Dispnéia expiratória sugere processos mórbidos que interferem na elasticidade de retorno pulmonar, ou que provoquem obstruções das pequenas vias aéreas, dificultando a saída do ar. É o que ocorre no enfisema pulmonar, nas bronquites e bronquiolites. A dispnéia mista manifesta-se na broncopneumonia. No edema pulmonar e na pneumonia intersticial, por serem enfermidades restritivas à expansão pulmonar, pode haver predomínio de dispnéia do tipo inspiratória, quando o processo é intenso (RADOSTITS et al., 1994).

O pulmão pode responder funcionalmente à diminuição das trocas gasosas por dois mecanismos compen- 
satórios: aumentando a frequiência respiratória (taquipnéia) e a amplitude torácica (hiperpnéia) respiratórias. A taquipnéia não ajuda a localizar a alteração dentro do aparelho respiratório, pois pequenas alterações anatômicas, por exemplo, as pneumonias focais, que determinam alterações nas trocas gasosas, já podem exacerbar esse mecanismo de defesa (RADOSTITS et al., 1994). A hiperpnéia, por sua vez, está relacionada principalmente a processos que dificultam a expansão pulmonar, como o pneumotórax, já que não havendo manutenção da pressão negativa intra-pleural, há necessidade de maior esforço para inspirar. Temporariamente, a hiperpnéia pode manifestar-se após exercício físico.

O tipo de respiração também nos dá indícios para a localização da doença. Os animais que manifestam dor torácica, relacionada à fratura de costela ou pleuris, podem apresentar respiração predominantemente abdominal, como forma de defesa contra a dor. Aqueles com dor abdominal, como nos casos de peritonite ou grandes compressões sobre o diafragma, podem exibir respiração do tipo costal (STÖBER, 1993).

A inspeção nasal é de grande importância no exame do aparelho respiratório. Deve-se observar as alterações do espelho nasal, dos tipos, ressecamento, como nos casos de febre e, hemorragias e erosões, como na febre catarral maligna (ANDREWS, 1992; RADOSTITS et al., 1994; REBHUN et al., 1995). No conduto nasal, deve-se pesquisar úlceras, erosões ou corpos estranhos, que podem ser vistos sob inspeção direta da cavidade nasal. $\mathrm{Na}$ inspeção das narinas, o corrimento nasal pode fornecer informações sugestivas da localização do processo. Ele pode ser oriundo do trato respiratório alto ou baixo. Se for unilateral indica, provavelmente, alterações na narina correspondente, e os processos mais comuns são corpos estranhos, úlceras e ferimentos. Se bilateral, pode representar alterações de ambas as narinas, em especial os processos inflamatórios que aumentam a secreção nasal. Pode também estar vindo de locais abaixo ou atrás da narina, geralmente, laringe, traquéia e brônquios, relacionado a problemas que exacerbam a produção de secreções (PRINGLE, 1992a; STÖBER, 1993).

Quanto ao tipo, o corrimento nasal pode ser classificado em seroso, mucoso, purulento, hemorrágico e de conteúdo alimentar. O corrimento seroso é o tipo de corrimento comum em bovinos, que, como se sabe, lambem constantemente as narinas. Assim, este corrimento é visto com mais intensidade naqueles animais que se apresentam deprimidos, por problemas que podem não estar relacionados ao aparelho respiratório. Corrimento nasal mucoso relaciona-se à maior produção de muco pelas glândulas das narinas estimulada por inflamações (BRYSON et al., 1979; BELKNAP, 1993; CRANDELL, 1993). O corrimento nasal torna-se purulento quando há contaminação bacteriana e migração de células leucocitárias para o local. Lesões vasculares provocadas por corpos estranhos, ferimentos, úlceras ou pólipos, podem determinar corrimento do tipo hemorrágico. Às vezes, os bovinos apresentam corrimento nasal com conteúdo alimentar e restos de capim, apresentando coloração esverdeada e odor variável (desde ausência até putrefação). Este tipo de corrimento demonstra defeitos na deglutição por faringite ou processos obstrutivos de esôfago e o animal apresenta refluxo nasal, principalmente quando deglute (BRAZ, 1981; STÖBER, 1993).

Ainda, no exame das narinas, deve-se atentar para o odor da respiração e o fluxo do ar exalado. Odor pútrido à expiração está relacionado com lesões necrosantes tais como laringite necrótica, abscesso pulmonar ou pneumonia por aspiração (LOPEZ e BILDFELL, 1992). Fluxo de ar desigual nas narinas, visto de forma comparativa, implica diminuição de calibre de uma delas, que pode ser encontrado nas obstruções por corpos estranhos ou tumores (MAREK e MÓCSY, 1965; BRAZ, 1981; STÖBER, 1993).

A tosse, um dos mecanismos de limpeza do aparelho respiratório, ocorre quando há irritação das terminações nervosas da laringe e traquéia provocada pela inflamação da mucosa, seja por ação direta do agente agressor sobre a mucosa, seja pela produção excessiva de muco (PRINGLE, 1992a; STÖBER, 1993; RADOSTITS et al., 1994). A tosse seca geralmente acontece por alterações inflamatórias em vias aéreas superiores. É freqüente nos casos de faringite e laringite, podendo também se manifestar nas traqueítes. Tosse úmida ou produtiva relaciona-se a aumento de exsudato broncopulmonar, sendo comum nas broncopneumonias, onde o movimento das secreções nas vias aéreas está associado à respiração (ANDREWS, 1992; STÖBER, 1993).

\section{Palpação}

A palpação do aparelho respiratório inicia-se pelo reflexo de tosse. Nos bezerros, pode ser realizado beliscando-se ou esfregando-se os primeiros anéis traqueais logo abaixo da glote. Nos bovinos adultos, com o enrijescimento dos anéis cartilaginosos da traquéia, a maneira mais fácil de se provocar tosse é a obliteração do ar inalado até o animal reagir. $\mathrm{A}$ inspiração rápida de grande quantidade de ar provoca a tosse, se houver inflamação das vias aéreas (MAREK e MÓCSY, 1965; PRINGLE, 1992a). Recomenda-se palpar toda a parte externa do 


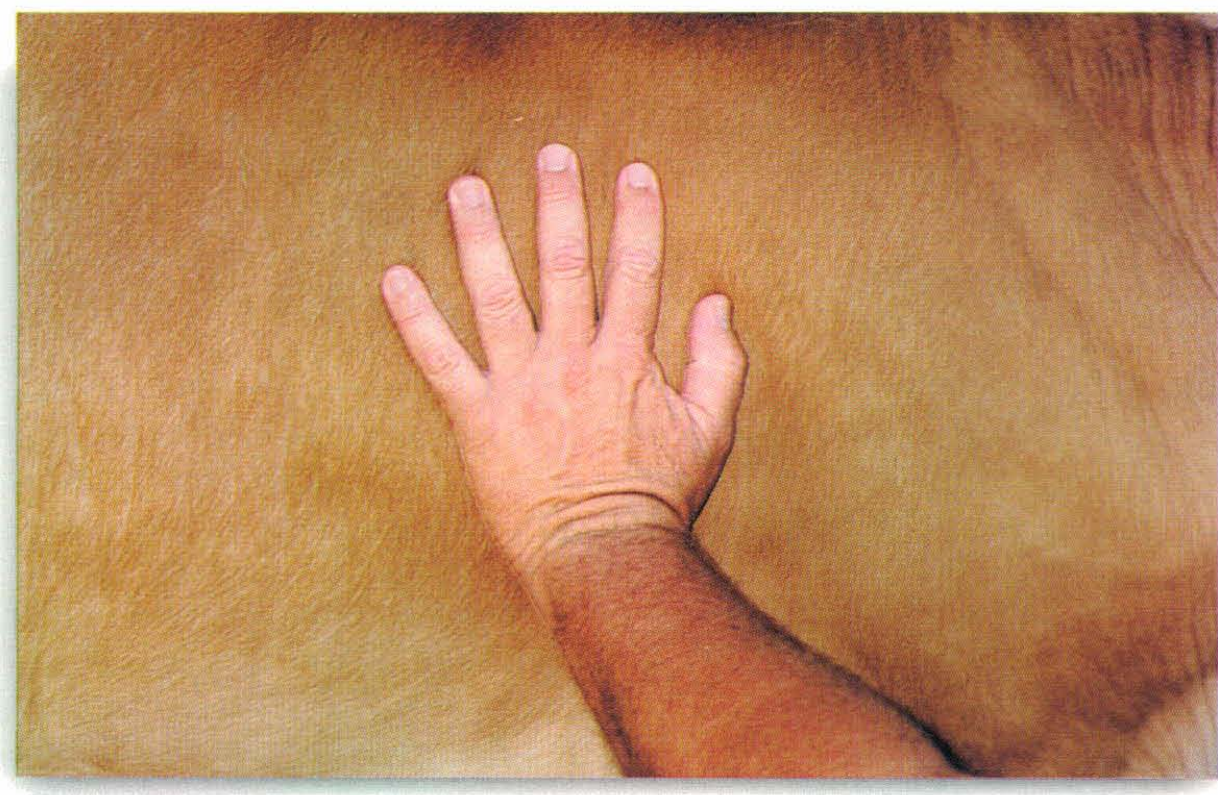

Figura 1: Palpação do gradil costal.

aparelho respiratório, à procura de depressões (afundamento do osso nasal, fratura de anel traqueal cervical, fratura de costelas) ou aumentos de volume, que possam ou não ter sido verificados à inspeção. Procuram-se sempre, nestas alterações superficiais, os sinais clássicos da inflamação. Se estes sinais forem detectados nos espaços intercostais, sem aumentos de volume nesta região, pode tratar-se de pleurite. A palpação do tórax deve ser feita com a mão espalmada e com a ponta dos dedos apoiada nos espaços intercostais. Aumenta-se gradativamente a pressão dos dedos e observa-se a reação do animal. Procura-se sentir ainda os frêmitos torácicos, relacionados a vibrações de grande quantidade de líquidos em brônquios ou provocados pelo atrito pleural (Figura 1). Na traquéia, pela palpação também pode detectar-se o chamado frêmito traqueal, originado geralmente por acúmulo de líquidos na traquéia (PRINGLE, 1992a; STÖBER, 1993).

\section{Percussão}

A percussão é um dos métodos semiológicos que fornece informações a respeito do estado físico do aparelho respiratório (MAREK e MÓCSY, 1965). Deve ser realizada desde os seios paranasais até o tórax. Nos seios paranasais (frontal e maxilar) a percussão deve ser feita com o cabo do martelo de per(Figura 2). cussão, de forma comparativa entre o lado esquerdo e o direito da cara do animal. A principal alteração que se consegue ouvir é a modificação do som normal (claro) para maciço, indicando que, uma cavidade, que antes era vazia, está sendo preenchida por alguma substância, por exemplo, com pus. É sinal indicativo de sinusite principalmente em bezerros após descornas, ou de tumorações em seio paranasal, em bovinos adultos (STÖBER, 1993).

No bovino, a resposta sonora à percussão do tórax pode variar desde o som normal (claro) até as suas alterações com significado clínico. Assim, áreas de sons submaciços a maciços podem indicar tecido pulmonar solidificado ou, pelo menos, quantidade diminuída de ar no órgão. Isto ocorre em casos de pneumonia ou de abscessos pulmonares. Áreas de som timpânico sugerem maior acúmulo de ar no pulmão, denotando enfisema ou pneumotórax. As anormalidades, para serem percebidas, devem ter no mínimo o tamanho de um ovo de galinha ou de um punho e estar próximas à parede torácica, pois o som produzido pela percussão tem uma penetração de até sete centímetros. $\mathrm{O}$ encontro de som maciço na parte inferior do tórax com limite horizontal é indicativo de líquido no espaço pleural, por exemplo, na pleuris exsudativa (PRINGLE, 1992; STÖBER, 1993)

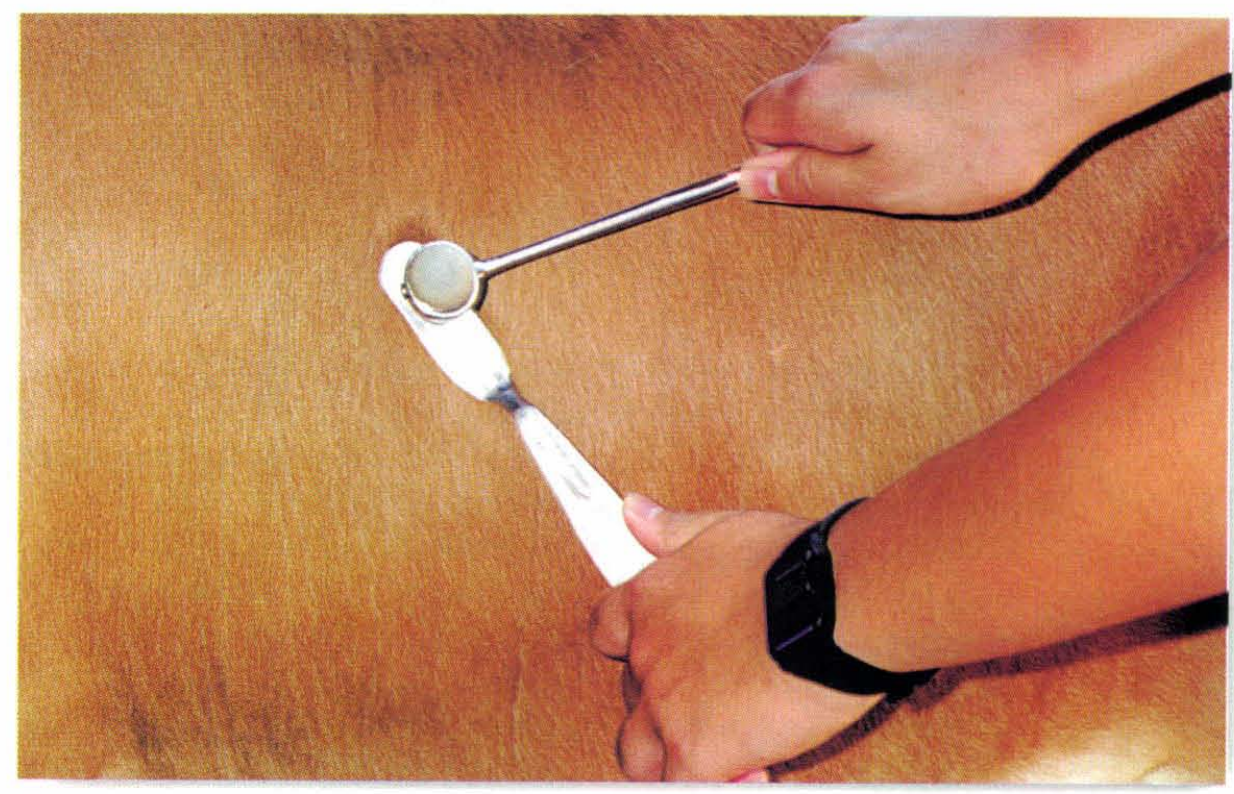

Figura 2: Percussão do tórax com martelo e plessímetro. 


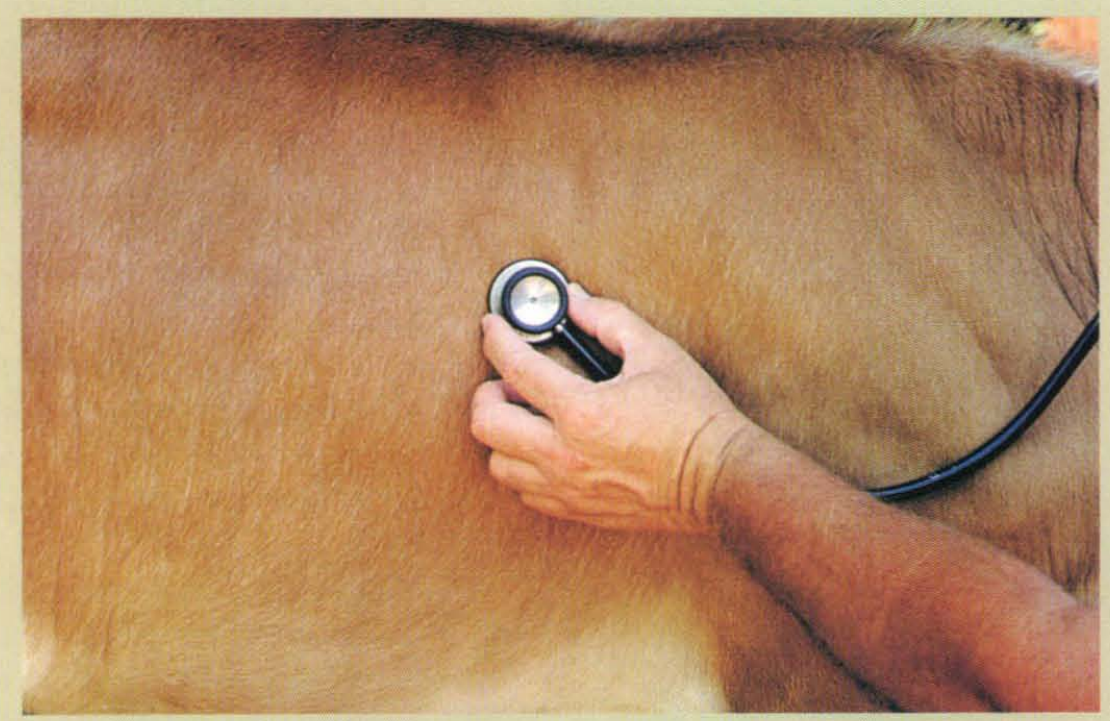

Figura 3: Auscultação dos pulmões.

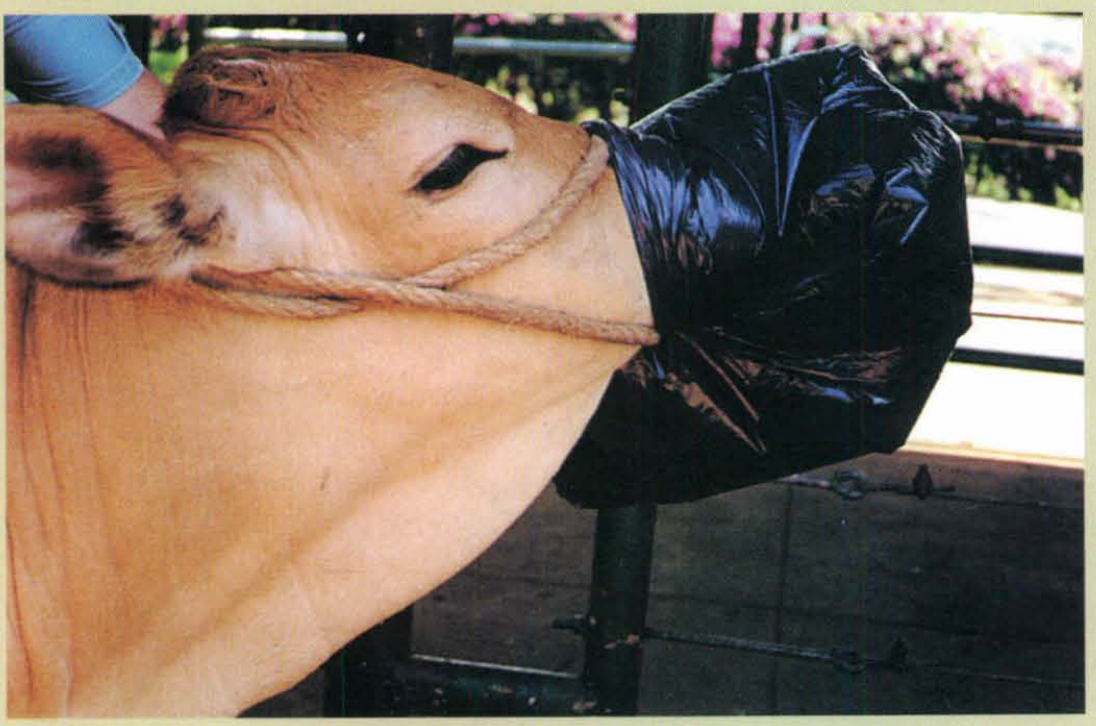

Figura 4: Uso do saco plástico no focinho.

\section{Auscultação}

A auscultação é o método diagnóstico que dá maiores informações a respeito do funcionamento do aparelho respiratório (ROUDEBUSH, 1982; HINCHCLIFF e BYRNE, 1991). A interpretação correta dos sons respiratórios pressupõe conhecimentos sobre sua produção e transmissão no trato respiratório normal, bem como dos efeitos que modificam o padrão normal dos sons produzidos (KOTLIKOFF e GILLESPIE, 1983).

Deve-se auscultar as vias aéreas anteriores e a região torácica separadamente, embora não se deva esquecer que pode haver interferência de auscultação de uma área sobre a outra, especialmente nos sons produzidos nas vias aéreas altas que podem interferir na auscultação pulmonar. Em vista disto, é bom lembrar que a origem de produção do som é o local onde se ouve com maior intensidade o ruído alterado (PRINGLE, 1992).

Para a realização da auscultação do trato respiratório, é necessário um ambiente silencioso, facilitando a completa concentração nas pequenas mudanças dos sons respiratórios (PRINGLE, 1992a). Para a realização dessa técnica utiliza-se o estetoscópio. A auscultação deve ser iniciada na traquéia e prosseguir para a área pulmonar, no sentido crânio-caudal e dorso-ventral, auscultando-se em cada local no mínimo dois movimentos respiratórios; dessa maneira é feita a auscultação de toda a área pulmonar. Em alguns casos, tornase necessária a inibição temporária da respiração do animal, obstruindo as narinas com as mãos, ou aplicando-se saco plástico envolvendo o focinho, para a intensificação dos sons respiratórios (STÖBER, 1993) (Figura 3 e Figura 4). Pode-se, também, usar-se um saco maior envolvendo o focinho, que além de aumentar o espaço morto respiratório, eleva o conteúdo de $\mathrm{CO}_{2}$ e diminui o de $\mathrm{O}_{2}$ do ar inalado, de tal maneira que há estimulação dos mecanismos de compensação respiratória e intensificação dos sons na auscultação.

Os sons auscultáveis são divididos em sons normais e em sons respiratórios patológicos. Os sons normais são produzidos pela turbulência do fluxo de ar e vibração das paredas das vias aéreas com mais de $2 \mathrm{~mm}$ de diâmetro (KOTLIKOFF e GILLESPIE, 1983; HINCHCLIFF e BYRNE, 1991). Variam na qualidade, dependendo da velocidade do ar e da quantidade de tecido sobre a área que se está ouvindo (CURTIS, 1986). Nas vias aéreas anteriores, ouve-se, sobre a traquéia, o som laringotraqueal, provocado pela vibração das paredes da laringe e traquéia, quando da passagem do ar. Patologicamente, pode-se ouvir o estertor ou estridor traqueal, provocado por acúmulo de líquido ou muco neste órgão, como se fosse o estourar de bolhas (PRINGLE, 1992a; STÖBER, 1993). 
$\mathrm{Na}$ área pulmonar, os sons respiratórios normais são perceptíveis em duas partes do tórax: no terço inicial, antes chamado de sopro laringotraqueal, glótico, bronquial ou tubário (MAREK e MÓCSY, 1965; BRAZ, 1981); é produzido pela vibração da parede dos grandes brônquios e, por isto, foi proposta por KOTLIKOFF e GILLESPIE, (1984) e CURTIS, (1986) a denominação de som bronquial; no terço final do tórax, o murmúrio vesicular, antes definido como sendo a penetração de ar em alvéolos (MAREK e MÓCSY, 1965) ou de "pequenos vasos" (ROUDEBUSH, 1982); com o intuito de simplificar, foi sugerido ainda o nome de som respiratório normal (KOTLIKOFF e GILLESPIE, 1984; CURTIS, 1986). A literatura atual, baseada nos mecanismos de produção e na localização, apresenta nova nomenclatura para os sons pulmonares. Denomina laringotraqueal, o som ouvido sobre a laringe e traquéia; traqueobrônquico, o som do terço anterior do tórax e, broncobronquiolar, o som presente nos dois terços posteriores do tórax (STÖBER, 1993).

Os sons patológicos do pulmão também sofreram modificações na sua nomenclatura. O estertor úmido está sendo denominado crepitação grossa e o estertor crepitante, crepitação fina. O estertor roncante, ou ronco, e o estertor sibilante, ou sibilo, são denominados simplesmente sibilos (LEHRER, 1990; HINCHCLIFF e BYRNE, 1991; STÖBER, 1993), o roce pleural, mudado para ruído pleural-respiratório, o sopro cardiopleural, para ruído cardiopleural e o sopro cardiopulmonar, para ruído cardiopulmonar (LEHRER, 1990; STÖBER, 1993). A despeito da nomenclatura modificada ou não, é necessário o conhecimento da fisiopatologia dos sons pulmonares. Se o clínico dominar a natureza diferenciada destes sons, certamente saberá identificar os normais e os patológicos, e diagnosticar os processos respiratórios.

\section{Significado Clínico dos Sons Respiratórios}

\section{Aumento de Intensidade dos Sons Normais do Pulmão}

Basicamente, o aumento de intensidade dos sons normais do pulmão à auscultação significa aumento na quantidade de ar que penetra neste órgão e, conseqüentemente, vibração maior das paredes das vias aéreas. Toda vez que houver modificação na respiração, ou por aumento na freqüência (taquipnéia), na amplitude (hiperpnéia) ou ainda, por dificuldade respiratória (dispnéia), haverá exacerbação na auscultação dos sons respiratórios. Os sons respiratórios normais podem estar exacerbados, também, nos casos em que haja facilitação de sua transmissão, especialmente quando houver líquido em in- terstício pulmonar, aumentando sua densidade como nas pneumonias e no edema pulmonar (KOTLIKOFF e GILLESPIE, 1984; PRINGLE, 1992).

\section{Diminuição de Intensidade dos Sons Pulmonares Normais}

Pode-se ter diminuição dos sons à auscultação pulmonar sempre que houver interferência na transmissão dos sons produzidos pelo órgão, ao ouvido de quem está auscultando. Estas barreiras podem advir de um processo fisiológico, como no caso de espessamento de tórax por depósito excessivo de gordura, de paredes torácicas mais musculosas, de animais de pêlos excessivamente longos ou na diminuição da velocidade de penetração do ar, conseqüentemente, menor vibração das paredes das vias aéreas, como nos animais em repouso.

Patologicamente, a diminuição de intensidade dos sons respiratórios pode acontecer nos casos em que haja aumento na distância entre o órgão produtor de som e o ouvido, por coleções de ar (enfisema torácico) ou de líquido (coleções pleurais de exsudato ou transudato) no espaço pleural. A diminuição de som pode ser tanta que, às vezes, é completamente abolido sendo chamado, à auscultação, de área de silêncio pulmonar. Acontece sempre na ausência de brônquios pérvios, como nos casos de broncopneumonia com obstrução de brônquios e nos casos em que haja compressões intensas por tumores ou grandes abscessos que não permitem a passagem do ar no pulmão (KOTLIKOFF e GILLESPIE, 1984; STÖBER, 1993).

\section{Sons Patológicos do Pulmão}

Além das alterações dos sons normais do pulmão, pode-se ouvir outros ruídos à auscultação.

CREPITAÇÃO GROSSA significa, clinicamente, o aumento de líquido no interior de brônquios, seja inflamatório ou não. $\mathrm{O}$ ar, ao passar pelos brônquios que estão com quantidade exagerada de líquido, determina a formação de uma onda, de tal maneira que há obstrução de sua luz. Como a pressão anterior e posterior a esta onda líquida é diferente, a tendência é que haja desobstrução da luz bronquial para em seguida haver nova obliteração, já que o ar continua entrando. O som provocado por estas obstruções e desobstruções seqüenciais assemelha-se ao estourar de bolhas, sendo por isto chamado de estertor bolhoso, ou ao sopro de ar em líquido, sendo então denominado de estertor úmido. Modernamente, por ser um ruído de crepitação, está sendo chamado de cre- 
pitação grossa (KOTLIKOFF e GILLESPIE, 1984; HINCHCLIFF e BYRNE, 1991; STÖBER, 1993). Ocorre nos casos de broncopneumonia, bronquites e no edema pulmonar.

CREPITAÇÃO FINA é o som semelhante ao esfregar de cabelos próximo à orelha, ou ao estourar de pequenas bolhas. Antigamente, acreditava-se que este som seria provocado pelo descolamento de alvéolos preenchidos por líquido inflamatório, se ocorresse durante a fase inspiratória da respiração (MAREK e MÓCSY, 1965). Mas, modernamente, sabendo-se que os sons respiratórios são produzidos em tubos de no mínimo 2mm (KOTLIKOFF e GILLESPIE, 1983; STÖBER,1993), deduz-se que este ruído seja produzido durante descolamento das pequenas vias aéreas preenchidas por líquido. Se ele for inspiratório, pode significar edema pulmonar ou pneumonia e, se expiratório ou inspiratório/expiratório (misto), doença pulmonar obstrutiva crônica e ou enfisema pulmonar (STÖBER, 1993).

RONCO é um som grave, de alta intensidade, produzido por secreções viscosas aderidas à parede de grandes brônquios, que vibram durante a passagem do ar. Este som pode indicar broncopneumonia, se sua origem, ou seja, o seu ponto máximo de auscultação estiver no tórax, ou mostrar laringite ou laringotraqueíte, se for melhor ouvido na região da laringe ou traquéia (KOTLIKOFF e GILLESPIE, (1984).

SIBILO é um som agudo, de alta intensidade, que se assemelha a um chiado ou a um assobio. Indica estreitamento de vias aéreas, causado por deposição de secreção viscosa aderida, que deforma a luz tubular, como se fosse um bico de flauta, ou ainda, broncoespasmo. Se ocorrer no início da inspiração, está relacionado a processos extratorácicos como estenose da laringe, compressão da traquéia ou muco espesso depositado nestes locais. Se aparecer no fim da inspiração ou expiração, pode indicar obstrução das pequenas vias aéreas, como nos casos de bronquite ou bronquiolite (HINCHCLIFF e BYRNE, 1991; STÖBER, 1993). LEHRER (1990) cita os sibilos polifônicos como sons graves, expiratórios, com variações de timbre e de alta intensidade, relacionando-os às alterações de calibre dos brônquios principais.

ROCE PLEURAL OU RUÍDO PLEURAL é o ruído provocado pelo atrito das pleuras visceral e parietal inflamadas, indicando uma pleurite. Num animal sadio, as pleuras deslizam suavemente umas sobre as outras, sem provocar ruído algum. Quando há inflamação e deposição de fibrina sobre elas, o atrito transmite-se ao ouvido do examinador como se fosse o esfregar de duas folhas de papel, couro molhado ou um gemido (STÖBER, 1993).

SOPRO, ROCE OU RUÍDO CARDIOPLEURAL é um ruído rude, semelhante ao raspar de duas superfícies ásperas, ouvido durante a inspiração e coincidente com a movimentação cardíaca. Corresponde ao atrito do pericárdio sobre a pleura inflamada, indicando portanto uma pleuris associada a uma pericardite (STÖBER, 1993).

SOPRO OU RUÍDO CARDIOPULMONAR é um ruído suave, de baixa intensidade, semelhante ao soprar com os lábios apertados. Conforme o ar passa nos brônquios menores, nas áreas pulmonares que estão sobre o coração, ele pode ser interrompido durante o período de contração isovolumétrica da sístole ventricular. Quando ocorre a sístole, a passagem do ar é liberada e ouve-se este som, interrompido, de forma seqüencial a cada novo início da sístole. Ocorre em animais sadios ou naqueles em que há excesso de produção de muco como na bronquiolite (STÖBER, 1993).

INSPIRAÇÃOO INTERROMPIDA são pequenas interrupções na inspiração, como se fosse o soluçar de uma criança chorando. Se durante a inspiração, ouvese este ruído, com o tórax movimentando-se de uma única vez, é indicação de obstrução seqüencial de brônquios, com líquido (muco) em quantidade não suficiente para provocar a crepitação grossa. Se ruído for ouvido com a parede torácica movimentando-se em dois tempos, é sugestivo de dor à inspiração (pleuris) ou excitação psíquica do animal (MAREK e MÓCSY, 1965; KOTLIKOFF e GILLESPIE, 1984).

\section{Exames auxiliares no diagnóstico}

Os exames complementares não substituem o exame clínico, mas em alguns casos tornam-se essenciais para a determinação do tipo de processo, do agente causal, da reação inflamatória presente e gravidade, auxiliando na escolha do tratamento mais adequado e no estabelecimento do prognóstico (WILSON, 1992; STÖBER, 1993; DIXON, 1997).

O HEMOGRAMA fornece informações esclarecedoras, principalmente indicar se a alteração respiratória é inflamatória ou não. De maneira geral, a presença de leucocitose com neutrofilia indica processo bacteriano e, se houver leucopenia com linfocitopenia, identifica processo viral (JAIN, 1993).

O exame PARASITOLÓGICO de fezes é indicado no diagnóstico de verminose pulmonar por Dictyo- 
caulus viviparus. A técnica indicada para detecção de larvas é a do tubo cônico de centrifugação, de UENO e GONÇALVES (1994). A migração de larvas de ascarídeos pode também facilitar o aparecimento de processos inflamatórios no pulmão.

A DETECÇÃO SOROLÓGICA DE ANTICORPOS, é usada principalmente para se detectar anticorpos contra agentes virais, que são potencialmente patogênicos para o aparelho respiratório; embora seja de grande auxílio para se descobrir a etiologia da doença, tem suas limitações. Um rebanho vacinado ou que tenha tido contato com o agente que se está pesquisando pode ser reagente para aquele antígeno, sem, no entanto, significar que o animal está doente. Muitos rebanhos têm título sorológico e durante o episódio de um problema respiratório a detecção de anticorpos não esclarecerá a sua etiologia. No entanto, a associação dos sinais clínicos com o resultado sorológico poderá fornecer fortes indícios para identificar o agente causal (MARTIN e BOHAC, 1986; DURHAN e HASSARD, 1990; DUBOVI, 1993).

O exame RADIOGRÁFICO é um exame não invasivo do tórax, estruturas intratorácicas e seios paranasais, que ajuda na identificação e definição das doenças intratorácicas e do trato respiratório superior (SWEENEY e SMITH, 1993). Mostra algumas alterações no aparelho respiratório e ajuda muito na avaliação do tipo e na localização da alteração e tamanho da área afetada. As radiografias torácicas são melhor realizadas em animais com pequeno porte, exigindo equipamentos especiais nos bovinos adultos (PRINGLE, 1992; SWEENEY e SMITH, 1993; AMES e HMIDOUCH, 1995)

A ULTRA-SONOGRAFIA TORÁCICA possibilita detectar abscessos, tumores, enfisema e problemas de pleura (efusão pleural) (PRINGLE, 1992a; AMES e HMIDOUCH, 1995).

A ENDOSCOPIA é hoje um grande auxílio no diagnóstico das doenças respiratórias. Permite a visualização e análise das características físicas e funcionais do aparelho respiratório, que, além de facilitar a colheita de secreções durante o exame, poderão servir para exames citológicos e diagnóstico do agente causal (PRINGLE, 1992).

O LAVADO TRAQUEOBRÔNQUICO E BRONCOALVEOLAR está intimamente associado com o exame físico por fornecer o acesso ao trato respiratório inferior, e desta maneira auxiliar no diagnóstico do agente causal, na avaliação da gravidade do processo inflamatório e consequiente prognóstico das doenças respiratórias (GONÇALVĖS, 1987; GONÇALVES et al., 1990; GONÇALVES, 1997).
As medidas de gases sangüíneos arteriais, denominada HEMOGASOMETRIA, são indicadas para documentar a insuficiência pulmonar, diferenciar hipoventilação de outras causas de hipoxemia, ajudar a determinar a necessidade de oxigenação e posteriormente para monitorizar a resposta à terapia (PRINGLE, 1992a; SWEENEY e SMITH, 1993). Para que as anormalidades atinjam valores mensuráveis, o comprometimento pulmonar deve ser grave, em virtude dos mecanismos compensatórios de defesa do organismo (SWEENEY e SMITH, 1993).

BIOPSIA PULMONAR é indicada para obtenção de diagnóstico histológico, ou para informações prognósticas, principalmente em casos de moléstia pulmonar difusa, visto que a amostra obtida é muito pequena (SWEENEY e SMITH, 1993). Segundo PRINGLE (1992) e LARKIN (1994), em casos de lesões focais, como nas neoplasias, a colheita deve ser guiada por ultra-som ou endoscopia. A biopsia pulmonar não deve ser realizada nos casos de hipertensão pulmonar, cistos, abscessos e coagulopatias (PRINGLE, 1992). Também deve ser evitado em animais com depressão grave, dispnéicos ou moribundos (LARKIN, 1994).

TORACOCENTESE é indicada para a colheita de amostras de derrame pleural, para remover o fluido pleural ou ar para a estabilização dos animais com a ventilação comprometida. As complicações da toracocentese são o pneumotórax causado pela laceração pulmonar, hemotórax ou piotórax iatrogênico (RADOSTITS et al., 1994) e são as mesmas da biópsia pulmonar.

A NECRÓPSIA é método seguro na pesquisa etiológica das afecções pulmonares nos bovinos. Consegue-se, com esse método, a visualização das lesões do aparelho respiratório e a colheita do material necessário para análises diagnósticas, tanto do tipo de lesão, como do agente causal. É bastante utilizada para o estudo da etiologia das afecções pulmonares em bezerros (TAVERA et al., 1982; LÓPEZ, 1995).

Com o uso cada vez maior dos métodos auxiliares, o clínico está adquirindo grande ajuda para o diagnóstico e estudo das doenças respiratórias dos bovinos. Muitos dos métodos apresentam custos muito altos ou são pouco práticos, e só se justificam em alguns animais. Outros, necessitam de estudos mais profundos para que sejam usados na rotina diagnóstica, mas sem dúvida, trabalhos futuros nesta área irão cada vez mais fornecer meios para que se consiga diagnósticos rápidos e seguros para as doenças respiratórias dos animais (PRINGLE, 1992a). 


\section{SUMMARY}

Infections of the respiratory tract are among the most common disease of calves, leading to large economic losses as a result of costs involve in diagnosis, treatment and loss of animals. In this study, history, inspection, palpation, percussion, auscultation and olfaction are described. Comments are made about some ancillary diagnostic procedures.

Key words: Bovine, calves, respiratory system, examination.

\section{REFERÊNCIAS BIBLIOGRÁFICAS}

1 - AMES, T.R.; HMIDOUCH, A. Pathophysiology and diagnosis of respiratory disease. In: KOBLUK, C.N.; AMES, T.R.; GEOR, R.J. The horse: diseases and clinical management. Philadelphia: W.B. Saunders, 1995. v. 1, cap. 12, p.199-212.

2 - ANDREWS, A.H. Calf respiratory disease. In: ANDREWS, A.H.; BLOWEY, R.W.; BOYD, R.G.; EDDY, R.G. (Eds). Bovine medicine: diseases and husbandry of cattle. Oxford: Blackwell, 1992. Cap. 15, p.202-12.

3 - BEECH, J. Equine respiratory disorders. Malven: Lea \& Febiger, 1991. 458p.

4 - BELKNAP, E.B. Recognizing the clinical signs of BRSV infection. Vet. Med., v.88, p.886-7, 1993.

5 - BRAZ, M.P. Semiologia médica animal. 2.ed. Lisboa: Fundação Calouste Gulbenkian, 1981. 644p.

6 - BREEZE, R. Parasitic bronchitis and pneumonia. Vet. Clin. North Am. Food Anim. Pract., v.1, p.277-87, 1985.

7 - BRYSON, D.G.; McFERRAN, J.B.; BALL, H.J.; NEILL, S.D. Observations on outbreaks of respiratory disease in calves associated with parainfluenza type 3 virus and syncytial virus infection. Vet. Rec., v.104, p.45-9, 1979.

8 - CRANDELL, R.A. Viral diseases of cattle. In: HOWARD, J.L. Current veterinary therapy 3: food animal practice. 3.ed. Philadelphia: W.B. Saunders, 1993. p.417-9.

9 - CURTIS, R.A.; VIEL, L.; McGUIRK,S.M.; RADOSTITS, O.M.; HARRIS, F.W. Lung sounds in cattle, horses, sheep, and goats. Can. Vet. J., v.27, p.170-2, 1986.

10 - DIXON, P.M. Ancillary diagnostic techniques for the investigation of equine pulmonary disease. Equine Vet. Educat., v. 9, p. 72-80, 1997.

11 - DUBOVI, E.J. Diagnosing BRSV infection: a laboratory perspective. Vet. Med., Sept., p.883-93, 1993.

12 - DURHAN, P.J.K.; HASSARD, L.E. Prevalence of antibodies to infectious bovine rhinotracheitis, parainflenza-3, bovine respiratory syncytial, and bovine viral diarrhea viruses in cattle in Saskatchewan and Alberta. Can. Vet. J., v.31, p.81520, 1990.

13 - GONÇALVES, R.C. Estudo da flora traqueobrônquica em bezerros clinicamente sadios e portadores de pneumonia, na região de Botucatu - SP. Botucatu, 1987. 44p. Dissertação (Mestrado) - Faculdade de Medicina Veterinária e Zootecnia, Universidade Estadual Paulista.

14 - GONÇALVES, R.C. Estudo clínico e citológico em bezerros clinicamente sadios e portadores de broncopneumonia moderada e grave. - O lavado traqueobrônquico como complemento diagnóstico- Botucatu. 1997. Tese (Doutorado) Faculdade de Medicina, UNESP.

15 - GONÇALVES, R.C.; KUCHEMBUCK, M.R.G.; ALMEIDA, C.T. Lavagem traqueobrônquica por traqueocentese em Bovinos. Vet. Zootec., v. 2, p. 17-25, 1990.

16 - GRIFFIN, B. Economic impact associated with respiratory disease in beef cattle. Vet. Clin. North Am.: Food Anim. Pract. v. 13, p. 367-76, 1997.

17 - HINCHCLIFF, K.W.; BYRNE, B.A. Clinical examination of the respiratory system. Vet. Clin. North Am.: Equine Pract., v. 7 , p. $1-25,1991$.

18 - JAIN, N.C. Essentials of veterinary hematology. Philadelphia: Lea \& Febiger, 1993, 417p.

19 - JONES, C.R.; WEBSTER, A.J.F. Weather - induced changes in airborne bacteria within a calf house. Vet. Rec., v.109, p.4934, 1981.

20 - KOTLIKOFF, M.I.; GILLESPIE, J.R. Lung sounds in veterinary medicine: Part I. Terminology and mechanisms of sound production. Comp. Cont. Educ. Pract. Vet., v.5, p.634-44, 1983.

21 - KOTLIKOFF, M.I.; GILLESPIE, J.R. Lung sounds in veterinary medicine: Part II. Deriving clinical information from lung sounds. Comp. Cont. Educ. Pract. Vet., v.6, p.462-7, 1984.

22 - LARKIN, H.A. Veterinary Citology - cytological diagnosis of diseases of respiratory tract in animals. Irish Vet. J., v.47, p.304-12, 1994. 
23 - LEHRER, S. Entendendo os sons pulmonares. São Paulo: Roca, 1990. 147p.

24 - LOPEZ, A. Respiratory system. In: CARTON, W.W.; McGAVIN, M.D. Thomson's special veterinary pathology. 2.ed. St. Louis: Mosby, 1995. 116-74.

25 - LOPEZ, A.; BILDFELL, R. Pulmonary inflammation associated with aspirated meconium and epithelial cells in calves. Vet. Pathol., v.29, n.2, p.104-11, 1992.

26 - MAREK, J.; MÓCSY, J. Tratado de diagnóstico clínico de las enfermidades internas de los animales domésticos. 3.ed. Barcelona: Labor, 1965. p. 25-6. Antecedentes conmemorativos. Anamnesis.

27 - MARTIN, S.W.; BOHRAC, J.G. The association between serologic titers in infectious bovine rhinotracheitis virus, bovine virus diarrhea virus, parainfluenza-3 virus, respiratory syncytial virus and treatment for respiratory disease in Ontario feedlot calves. Can. J. Vet. Res., n.50, p.351-8, 1986.

28 - PINSENT, P.J.N. Diagnosis and differential diagnosis in the cow. In: ANDREWS, A.H.; BOYD, H.; BLOWEY, R.W.; EDDY, R.G. Bovine medicine: disease and husbandry of cattle. Oxford: Blackwell, 1992. Cap.9, p 107-33.

29 - PRINGLE, J.K. Ancillary testing for the ruminant respiratory system. Vet. Clin. North Am.: Food Anim. Pract., v. 8, p. 243-55, 1992.

30 - PRINGLE, J.K. Assessment of the ruminant respiratory system. Vet. Clin. North Am.: Food Anim. Pract., v. 8, p. 233-43, 1992a.

31 - PRINGLE, J.K.; BRIGHT, J.M.; DUNCAN, R.B.Jr.; KERR, L.; LINNABARY, R.D.; TARRIER, M.P. Pulmonary hypertension in a group of dairy calves. J. Am. Vet. Med. Assoc., v.198, p.857, 1991.
32 - RADOSTITS, O.M.; BLOOD, D.C.; GAY, C.C. Veterinary medicine. 8.ed. London: Baillière Tindall, 1994. cap. 1, 1763 p.

33 - REBHUN, W.C.; GUARD, C.; RICHARDS, C.M. Diseases of dairy cattle. Baltimore: Willians \& Wilkins, 1995. p 110: The clinical examination.

34 - RIBBLE, C.S.; MEEK, A.H.; JANSEN, E.D.; GUICHON, P.T.; JIM, G.K. Effect of time of year weather, and pattern of auction market sales on fatal fibrinous pneumonia (shipping fever) in calves in a large feedlot in Alberta (1985-1988). Can. J. Vet. Res., v.59, p.167-72, 1995.

35 - ROUdebush, P. Lung sounds. J. Am. Vet. Med. Assoc., v. 181, p. $122-6,1982$.

36 - STÖBER, M. Aparelho respiratório. In: ROSENBERGER, G. Exame clínico dos bovinos. 3.ed. Rio de Janeiro: Guanabara Koogan, 1993. p.139-65.

37 - SWEENEY, C.R.; SMITH, J.A. Moléstias do sistema respiratório. In.SMITH, B.P. Tratado de medicina interna de grandes animais. São Paulo: Manole, 1993. v.1, p.501-17.

38 - TAVERA, E.T.; TAVERA, F.T.; LUGO, G.H.; CASILLAS, C.R.; VILLA-LOBOS, M.B. Patologia y bacteriologia de pulmones neumónicos de becerros. Vet. Mex., v.13, p.131-40, 1982.

39 - UENO, H.; GONÇALVES, P.C. Manual para diagnóstico das helmintoses de ruminantes. 3.ed. Porto Alegre: Japan International Cooperation Agency, 1994. 166p.

40 - WILSON, J.H. The art of physical diagnosis. Vet. Clin. North Am.: Food Anim. Pract. v. 8, p. 169-76, 1992.

41 - WILSON, W.D.; LOFSTEDT, J. Alterations in respiratory function. In: SMITH, B. Large animal internal medicine: diseases of horses, cattle, sheep and goats. St. Louis: C.V. Company, 1990, v.1, p.47-99.

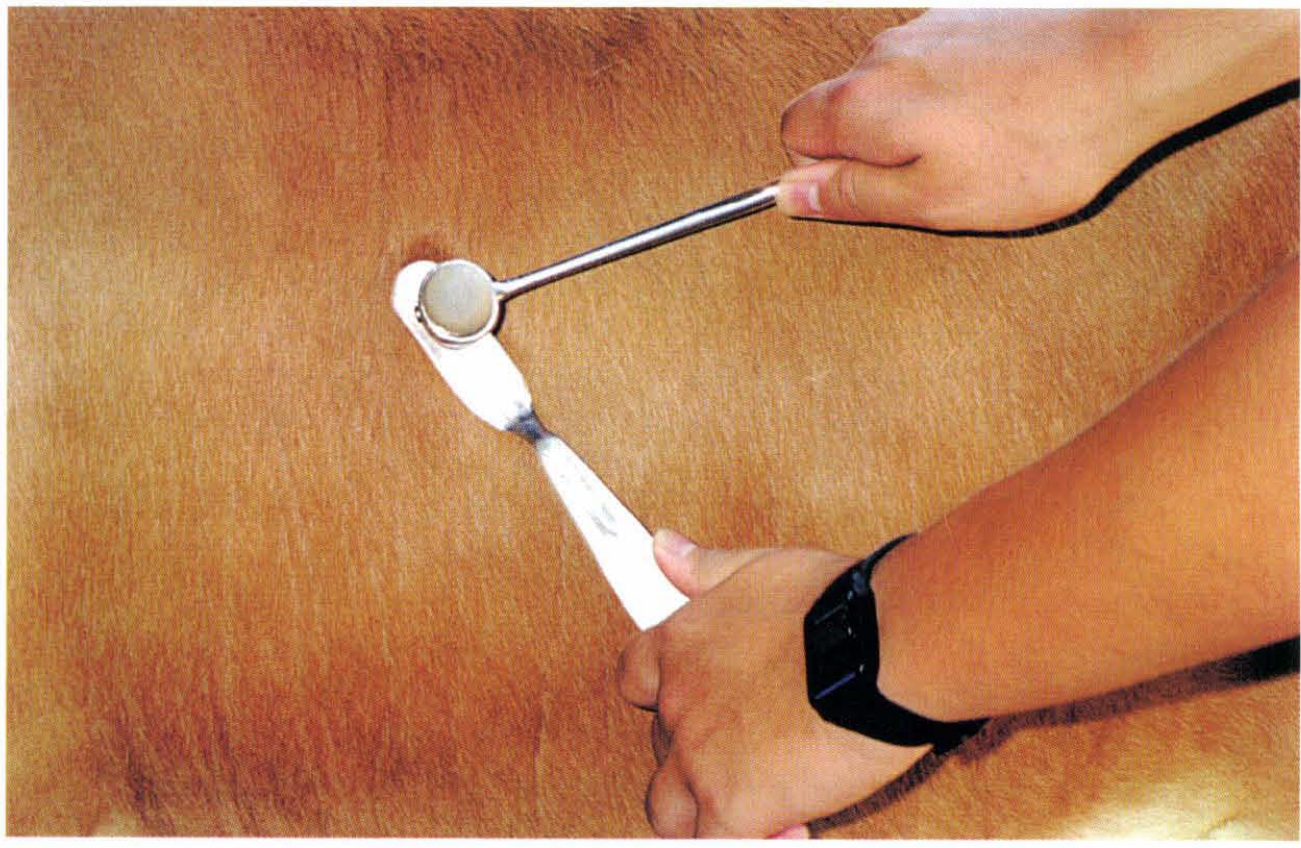

